\title{
DIREITOS SEXUAIS E REPRODUTIVOS E A POLÍTICA PÚBLICA DE SOCIOEDUCAÇÃO: POSSIBILIDADES PARA A PREVENÇÃO DA VIOLÊNCIA EM RELACIONAMENTO ÍNTIMO
}

\author{
SEXUAL AND REPRODUCTIVE RIGHTS AND THE SOCIO- \\ EDUCATION PUBLIC POLICY: POSSIBILITIES FOR THE \\ PREVENTION OF VIOLENCE IN INTIMATE RELATIONSHIPS
}

\author{
Sheila Giardini Murta ${ }^{1}$ \\ Silvia Renata Lordello ${ }^{2}$ \\ William Gualberto Gonçalves de Souza ${ }^{3}$
}

\begin{abstract}
RESUMO
O presente ensaio se propõe a refletir sobre prevenção da violência em relacionamento íntimo como meio de garantia de acesso a direitos sexuais e reprodutivos pelo público feminino na Política Pública de Socioeducação no Brasil. Para isso, desenvolve-se um resgate de marcos legais e evidências científicas relevantes que podem embasar o desenvolvimento das respectivas propostas de intervenções preventivas. As reflexões apresentadas consubstanciam-se na indicação de um percurso para a criação de propostas de prevenção à violência em relacionamentos íntimos aplicável à socioeducação. Observa-se que o diálogo entre a ciência da prevenção e a política pública de socioeducação é profícuo para pensar a garantia de acesso a direitos sexuais e reprodutivos, pois destaca-se a necessidade de romper com práticas violadoras baseadas em aspectos culturais (cultura patriarcal, adultocentrismo e heteronormatividade). Portanto, compreende-se que as reflexões presentes no texto podem promover avanços no alcance de acesso a viver a própria sexualidade sem sofrer violências ao analisar novas alternativas para sua garantia a partir do atendimento psicossocial.
\end{abstract}

Palavras-chaves: Direitos sexuais e reprodutivos; Políticas públicas; Socioeducação.

\footnotetext{
1 Atualmente é Professora Associada no Departamento de Psicologia Clínica do Instituto de Psicologia da Universidade de Brasília. Pós-Doutora pela Universidade Federal de São Carlos (2010), Universidade de Maastricht - Holanda (2014) e Oxford Brookes University - Reino Unido (2019). Doutora em Psicologia Social e do Trabalho pela Universidade de Brasília. e-mail: giardini@unb.br

2 Atualmente é docente do Programa de Pós-Graduação em Psicologia Clínica e Cultura e da graduação em Psicologia na Universidade de Brasília. Doutora em Psicologia Clínica e Cultura pela Universidade de Brasília. Mestra em Psicologia do Desenvolvimento pela Universidade de Brasília. e-mail: srmlordello@gmail.com

${ }^{3}$ Atualmente é Especialista Socioeducativo - Psicologia na Secretaria de Estado de Justiça e Cidadania Distrito Federal. Mestre em Psicologia Clínica e Cultura pela Universidade de Brasília. e-mail: william.psi.88@gmail.com
} 


\begin{abstract}
This essay reflects on the prevention of violence in intimate relationships to guarantee the female population's sexual and reproductive rights in socio-education public policy in Brazil. Based on a review of legal frameworks and relevant scientific evidence, preventive interventions are proposed. The reflections pave the way for creating social-education proposals for violence prevention in intimate relationships. A dialogue between the prevention science and the socio-education public policy is instrumental in thinking about guaranteeing access to sexual and reproductive rights, as it highlights the need to break with violating practices based on cultural aspects (patriarchal culture, adult-centrism, and heteronormativity). By analyzing the guarantee to new psychosocial care alternatives, the reflections in this article can promote advances in female access to living their sexuality without suffering violence.
\end{abstract}

Keywords: sexual and reproductive rights; public policy; socio-education.

\title{
INTRODUÇÃO
}

O presente ensaio se propõe a analisar e refletir sobre prevenção da violência em relacionamento íntimo como um dos meios de garantia de acesso a direitos sexuais e reprodutivos pelo público feminino na Política Pública de Socioeducação. Avalia-se, portanto, existir espaço para a realização de intervenções preventivas no âmbito do atendimento socioeducativo destinado a adolescentes de sexo feminino. Nesse sentido, percebe-se uma potencialidade do diálogo entre a socioeducação e a ciência da prevenção no que concerne à produção de intervenções baseadas em evidências científicas. Assim, para além de possíveis benefícios econômicos das intervenções preventivas, destaca-se a possibilidade de qualificar o atendimento prestado a esse público, uma demanda que tem sido assinalada em documentos oficiais (BRASIL, 2013).

O percurso metodológico que embasou a construção do presente texto consolidou-se com a prática profissional do primeiro autor, psicólogo do sistema socioeducativo há 10 anos. Nesse período de atuação, por cerca de dois anos e meio, o profissional dedicou-se ao atendimento do público feminino em responsabilização na medida socioeducativa de internação. Em decorrência da prática profissional, a violência em relacionamentos íntimos tornou-se evidente. O presente ensaio, portanto, constitui-se como produto da experiência profissional e trajetória de estudos acadêmicos (orientada pelas coautoras do texto).

Assinala-se, inicialmente, a pequena produção acadêmica a respeito da ocorrência de violência no namoro em relacionamentos de adolescentes que cumprem medida 
socioeducativa. A lacuna, destaca-se no que tange à categoria "adolescente em conflito com a lei”, pois essa fala de um modo de adolescer que tem uma trajetória com destaque às iniquidades que sobre ela incidem e a resposta que o adolescente apresenta na relação com sua condição de existência (CUNHA; LOPES DE OLIVEIRA e BRANCO, 2020). Ao restringir por gênero (feminino) a categoria "adolescente em conflito com a lei", busca-se a visibilização de uma minoria dentro do universo do cumprimento de medidas socioeducativas. Nesse sentido, é conveniente destacar que o levantamento de dados a respeito do sistema socioeducativo nacional (SINASE) ainda é recente e provoca reticências quanto à fidedignidade dos dados, dentro desse período a segmentação por gênero é ainda mais recente (ARRUDA, 2021).

A pertinência do tema decorre de a população em medida de responsabilização pelo cometimento de infração apresentar relatos mais frequentes de terem sido vítimas de diferentes formas de violência em relacionamento íntimo, quando comparada à população que não está em processo de responsabilização (SCHINDELE e LINDROTH, 2021). Além disso, a estruturação dos sistemas que comportam restrição da liberdade, tendem a invisibilizar e, algumas vezes inviabilizar o acesso a direitos sexuais e reprodutivos, em especial, quando se trata do público feminino (LOURENÇO et al., 2018; RE e CIUFFOLETTI, 2020; REIS e ZUCCO, 2019). Nesse sentido, os primeiros obstáculos enfrentados ao se propor a garantia do acesso a direitos sexuais e reprodutivos são aspectos institucionais e culturais que não os reconhecem à pessoa em condição de encarceramento, quadro que se agrava ao se tratar de adolescentes e mulheres (REIS e ZUCCO, 2019; LOURENÇO et al., 2018).

O Brasil, enquanto signatário de conferências internacionais, ratifica os direitos sexuais e reprodutivos como a garantia do exercício voluntário da própria sexualidade recebendo respeito, sem sofrer violência e com acesso à atenção em saúde (BRASIL, 2015). São exemplos de direitos sexuais e reprodutivos o direito à orientação sexual, o planejamento familiar, a escolha do parceiro, o exercício voluntário da sexualidade, o acesso a métodos contraceptivos ou a meios que favoreçam a reprodução, entre outros. Esse rol de direitos se relaciona, no contexto da adolescência, com a oportunidade desenvolvimental de exercício da 


\section{Revista \\ Debates Insubmissos}

sexualidade, a qual ancora novos modos de interação (afetivo-sexuais) e pode modificar a compreensão a respeito da própria identidade (no que concerne à identidade de gênero e orientação sexual) (JIMENEZ; ASSIS e NEVES, 2015). O exercício da sexualidade na adolescência, não obstante, circunscreve-se à forma como a sociedade compreende o ser adolescente.

Existe na legislação brasileira compreensão de que para a população adolescente deve ser destinada proteção para garantir o pleno desenvolvimento de potencialidades humanas (BRASIL, 1990). É possível perceber na sociedade, entretanto, uma visão estereotipada e desqualificadora da população adolescente, representando-a frequentemente como altamente passional, emotiva, irritável, inconsequente e com baixa racionalidade (SHOEN-FERREIRA e SILVARES, 2010). De acordo com Lordello e Mauch (2020), é preciso problematizar os conceitos universalistas e deterministas que restringem a adolescência a uma fase estanque e passar a considerar as adolescências plurais. Nessa visão, as adolescências são vistas como um espectro multifacetado, cercado de possibilidades e vivências significativas, que são costumeiramente desprezadas e deslegitimadas pela sociedade. Segundo Rodriguez e Damásio (2014), esse momento do desenvolvimento vai muito além das mudanças pubertárias, pois compreende um profícuo movimento de construção da identidade e de investimento no sentido de vida do sujeito, com a experimentação de novos papéis, acrescidos de ganho de autonomia e mudanças nos laços socioculturais. Alguns estudos sobre adolescências destacam a importância desse momento para intervenções e reflexões oportunas pela natureza provisória dessas experiências, que podem se configurar em ensaios sobre a identidade que está sendo construída e que pode se beneficiar de espaços dialógicos, interventivos (LORDELLO; SOUZA e COELHO, 2019; CERQUEIRA-SANTOS; NETO e KOLLER, 2014; CARRETEIRO, 2010). Além disso, os espaços da intervenção podem se configurar como diferenciais que combatam estereótipos, tornando-se fontes de suporte social que sejam recursivos aos adolescentes.

Ao cometer um ato infracional (conduta descrita como crime ou contravenção penal que foi praticado por adolescente entre 12 e 18 anos incompletos), o(a) adolescente se insere 
em uma circularidade da violência de alta letalidade, a qual tem marcadores das relações de gênero e vitimiza de modo proeminente as juventudes negras da periferia (MINAYO, 2005; BARROS et al., 2017). Ao adolescente que cometeu uma infração associa-se a representação de periculosidade que negligencia a reflexão sobre os aspectos históricos e sociais do envolvimento com atos infracionais (BARROS et al., 2017). Em contraponto a essa representação, registra-se que a minoria dos atos infracionais é cometida com violência ou grave ameaça (ARRUDA, 2021). A maior parte dos atos infracionais destaca-se por relacionar-se com a aquisição de renda pelo cometimento de roubo ou do comércio de drogas. A condição brasileira de graves desigualdades sociais, portanto, tem fomentado fenômenos como a juvenilização e feminilização do comércio de drogas, salientando ser fundamental a garantia de direitos previstos nos dispositivos legais como principal ação a ser destinada a população de crianças e adolescentes (ARRUDA, 2021; COSCIONI, et al., 2019).

O SINASE compreende a organização dos órgãos e políticas dedicados a promover o processo de responsabilização ao adolescente que cometeu um ato infracional (BRASIL, 2012). O estabelecimento legal da Política Pública de Socioeducação ocorreu há menos de uma década com a criação da Lei Sinase. A referida lei não foi o ato inaugural do processo de responsabilização a adolescentes pelo cometimento de infrações legais. Anterior ao Estatuto da Criança e do Adolescente (ECA) e ao SINASE, o Código de Menores construía um arcabouço penalizador destinado às crianças e adolescentes que viviam em condições tidas como irregulares; nesse sentido, o mecanismo legal anterior ao ECA servia como instrumento de controle, coerção e punição às camadas mais empobrecidas da população (BRASIL, 2006). O ECA e a Lei Sinase, por outro lado, são importantes dispositivos para rompimento com essa lógica e fomentam a perspectiva de proteção integral a crianças e adolescentes, tornandoos sujeitos de direitos.

Dentre o rol de direitos garantidos pela Lei Sinase, consta a garantia da assistência integral à saúde de adolescentes que estão em cumprimento de medida socioeducativa. $\mathrm{O}$ referido dispositivo dá destaque ao desenvolvimento de ações preventivas e de garantia à saúde sexual e reprodutiva. Dentre os agravos à saúde do adolescente considerados 
preveníveis, inclui-se a prevenção à Infecções Sexualmente Transmissíveis (ISTs) (BRASIL, 2012). Apesar da sinalização normativa, observa-se a invisibilização da saúde sexual do adolescente em conflito com a lei, pois está ausente uma perspectiva de garantia de direito do exercício sexual prazeroso e livre de vitimização por violência. Nesse sentido, o dispositivo legal aproxima-se de uma visão organicista a respeito da sexualidade, não abarcando a dimensão desenvolvimental e psicossocial do exercício da sexualidade (JIMENEZ; ASSIS e NEVES, 2015).

A lacuna observada condiciona o aumento de vulnerabilidade aos adolescentes que estão em cumprimento de medida socioeducativa, pois não se destina uma atenção complexa às demandas desse período de desenvolvimento. A dimensão da vulnerabilização pode se tornar ainda mais relevante quando se trata do público feminino, o qual tem recebido menor atenção na implementação da Política Pública de Socioeducação e que, devido a uma cultura patriarcal, pode vivenciar experiências de violência com uma frequência e intensidade superior ao público masculino (HERRERA e STUEWIG, 2017). Além da dimensão da violência, é possível que o público feminino tenha menor acesso a discursos que destaquem o exercício da sexualidade para além dos padrões orgânicos, discutindo aspectos da identidade, do respeito e do prazer (MORAES e BRÊTAS, 2016).

No âmbito do cotidiano institucional de uma unidade de internação, observam-se obstáculos logísticos e de gestão ao acesso à rede de atenção em saúde comunitária (COSTA e SILVA, 2017). A dificuldade de acesso à rede de saúde, aumenta a frequência do uso de estratégias unicamente medicamentosas. Nesse sentido, carece-se de intervenções psicossociais que promovam o desenvolvimento de habilidade e competências, inclusive, de reconhecimento da violência e seu impacto na trajetória de vida pessoal (COSCIONI, et al., 2018). O subfinanciamento da política de socioeducação associada à ausência de propostas que deem destaque ao caráter pedagógico da medida socioeducativa ocasionam que o fazer da equipe de acompanhamento do adolescente em medida socioeducativa seja ocupado por tarefas burocráticas, com ênfase na elaboração de relatórios (COSCIONI, et al., 2018). Esse 


\section{Debates Insubmissos}

Revista

panorama torna ainda mais necessária a reflexão a respeito de como estruturar estratégias de intervenção psicossocial.

Além disso, o envolvimento feminino com atos infracionais se configura como um evento que rompe com os estereótipos das relações de gênero e implica em uma representação desqualificadora dessa adolescente (COSTA, 2015; FROEMMING, 2016; JAVDANI; SADEH e VERONA, 2011). A dinâmica do envolvimento, entretanto, corrobora com a desigualdade das relações de gênero, criando-se paradoxos entre o rompimento e a manutenção dos estereótipos (BARCINSKI, 2009). Nesse sentido, a punição moral dirigida a mulheres e adolescentes do sexo feminino em processos de responsabilização por cometimento de infrações tem marco simbólico de expiação por romperem com a lógica tradicional das relações de gênero (DINIZ, 2017), sendo conveniente que as instituições que atendem o público feminino reflitam em seu funcionamento como reiteram a desigualdade das relações de gênero (LOPES DE OLIVEIRA; COSTA e CAMARGO, 2018), inclusive, no que tange à dinâmica nas relações afetivo-sexuais.

Existem poucos registros de intervenções preventivas focadas na violência pelo parceiro íntimo aplicadas ao contexto de responsabilização de adolescentes em conflito com a lei. Dentre essas, ressalta-se a proposta de Kelly et al. (2007), realizada no contexto da justiça juvenil norte-americana. A intervenção buscou reduzir comportamentos de risco sexual e também promover a prevenção da vitimização por violência em relacionamento íntimo, a partir de um método experimental com duas condições de estudo e grupo controle. A primeira condição utilizava como método de intervenção a exposição de vídeos, enquanto a segunda usava metodologia ativa de educação em saúde. A proposta teve indicadores de eficácia associados ao relato de aumento da adesão ao uso de preservativo em relações sexuais. Além disso, depois da intervenção houve redução do relato de vitimização por violência em relacionamento íntimo. A estratégia mostrou-se bem-sucedida, sendo que o grupo cuja intervenção foi aplicada com formas ativas de educação em saúde demonstrou melhores resultados do que aquele exposto a estratégias informacionais. As autoras, entretanto, 


\section{Revista
Debates Insubmissos}

registraram que a cultura coercitiva e punitiva inerente à instituição de responsabilização das adolescentes foi um dos importantes obstáculos enfrentados.

No âmbito brasileiro, também têm surgido propostas de prevenção à violência no namoro com indicadores de efeitos positivos, ainda que não específicas para adolescentes que cometeram atos infracionais. Murta et al. (2016), ao aplicar uma intervenção para prevenção à violência no namoro em adolescentes de uma escola pública, descreveu resultados de rompimentos da adesão aos comportamentos que se alinham aos papéis tradicionais de gênero, aumento do interesse por utilizar estratégias não violentas para resolução de conflitos, e desenvolvimento de habilidades interpessoais. Cita-se, porém, que estratégias preventivas para a realidade brasileira têm sofrido limitações em sua disseminação, fazendo com que o público que se beneficia de seus resultados ainda seja diminuto (Abreu \& Murta, 2016) e, dentre os poucos beneficiados, encontram-se ausentes as adolescentes que cometeram atos infracionais.

Avalia-se, portanto, a pertinência em analisar a prevenção da violência em relacionamento íntimo como meio de garantia de acesso a direitos sexuais e reprodutivos pelo público feminino na política pública de Socioeducação. Para tanto, este ensaio foi estruturado em três partes. Inicialmente, apresenta-se uma seção sobre a Política Pública de Socioeducação. Em seguida, são descritas evidências provenientes de pesquisas com vistas a refletir sobre marcos para a estruturação de uma intervenção preventiva à violência em relacionamento íntimo dentro da política pública de Socioeducação. A reflexão é estruturada em uma figura que busca sistematizar indicadores importantes no desenho de intervenções. Por fim, lançam-se algumas considerações a respeito dos impactos da prevenção de vitimização em relacionamento íntimo no atendimento socioeducativo. 


\section{DISPOSIÇÕeS LEgaIS E PEDAgógicAs DA POLÍtica PÚBLICA DE SOCIOEDUCAÇÃO}

A Política Pública de Socioeducação se embasa na compreensão constitucional de que às crianças e adolescentes deve ser dada absoluta prioridade no que tange à garantia de seus direitos sociais, bem como proteção quanto a exposição às condições adversas ao desenvolvimento (BRASIL, 1988). Nesse sentido, o ECA (BRASIL, 1990) preconiza amplo rol de direitos e estrutura um sistema de responsabilização especial para adolescentes que cometeram um ato infracional. O ECA garante ainda um rito judicial especial para apuração de responsabilidade e aplicação de Medida Socioeducativa pertinente (BRASIL, 1990). Nos casos em que se faça necessária a inserção em processo de responsabilização, caberá ao Juiz decidir entre as medidas socioeducativas aplicáveis, ponderando as circunstâncias e gravidade do ato infracional cometido, bem como a capacidade do adolescente para o efetivo cumprimento da Medida Socioeducativa (MSE) a ele atribuída.

O ECA instituiu seis medidas socioeducativas: 1- a advertência: consiste em uma admoestação verbal realizada em audiência; 2- a obrigação de reparar o dano: é realizada a partir do ressarcimento pelo(a) adolescente dos prejuízos patrimoniais ocasionados por seu comportamento; 3- a prestação de serviço à comunidade: se refere à realização gratuita de atividades de interesse geral em serviços governamentais, assistenciais ou congêneres, não podendo passar de oito horas de jornada semanal e nem seis meses de duração; 4- a liberdade assistida: pressupõe um acompanhamento sistemático por equipe especializada, a qual promoverá encaminhamentos e supervisão no que concerne à escolarização, profissionalização e inserção no mercado de trabalho, bem como avaliação da adesão às propostas a serem apresentadas por relatório encaminhado às autoridades judiciais em prazo não superior a seis meses (BRASIL, 1990). Além dessas, existem duas medidas socioeducativas que se caracterizam pela restrição parcial ou total da liberdade, quais sejam: 5

- a inserção no regime de semiliberdade que se caracteriza pela obrigatoriedade de vinculação a atividades escolares e profissionalizantes, sendo que o acesso aos serviços comunitários não requer autorização judicial prévia; 6 - a internação que deve ser realizada em estabelecimento 
educacional, sendo que o adolescente estará sob privação da liberdade. Tendo em vista a internação ser a mais gravosa das MSEs, sua aplicação deverá ser excepcional, breve e respeitará a condição peculiar de pessoa em desenvolvimento. A MSE de internação em estabelecimento educacional destina-se a casos que comportem: ato infracional cometido com violência ou grave ameaça; reiteração no cometimento de outras infrações graves; ou por descumprimento reiterado e injustificável de medida anteriormente imposta (BRASIL, 1990).

Além dos dispositivos mencionados, estão em vigor atualmente duas importantes normativas que regulam o sistema socioeducativo: a Lei Sinase - Sistema Nacional de Atendimento Socioeducativo (BRASIL, 2012) e a Resolução 119/2006 CONANDAConselho Nacional dos Direitos da Criança e do Adolescente (BRASIL, 2006). A Lei Sinase, em seu primeiro capítulo, pontua que as Medidas Socioeducativas têm por objetivo: a responsabilização do adolescente pelas consequências do cometimento de ato infracional; promoção da integração social e garantia de direitos; e a desaprovação da conduta infracional. Além disso, o diploma legal institui como se organizam as competências, o financiamento, planos, programas e a avaliação do sistema de atendimento socioeducativo.

Por outro lado, a Resolução 119/2006 - CONANDA traz a matriz pedagógica a ser observada no atendimento prestado ao adolescente em conflito com a lei. Dentre os eixos pedagógicos a serem contemplados na oferta do atendimento socioeducativo, constam, entre outros (BRASIL, 2006): a prevalência da ação socioeducativa sobre os aspectos meramente sancionatórios; a participação dos adolescentes na construção, no monitoramento e na avaliação das ações socioeducativas; a organização espacial e funcional das unidades de atendimento socioeducativo que garantam possibilidades de desenvolvimento pessoal e social para o adolescente; a diversidade étnico-racial, de gênero e de orientação sexual norteadora da prática pedagógica; e a participação ativa da família e da comunidade na experiência socioeducativa. O Plano Nacional de Atendimento Socioeducativo (BRASIL, 2013), por seu turno, demonstra em todas as suas metas a necessidade de qualificar o atendimento ofertado à população; porém, não apresenta meta específica no que concerne ao público feminino e suas relações. 
Um documento que responde a essa lacuna é a Recomendação do Mecanismo Nacional de Prevenção e Combate à Tortura, de 2013 (BRASIL, 2019). O texto é um marcador importante que salienta a necessidade de inauguração de unidades destinadas exclusivamente ao público feminino, nas quais devem existir contundentes ações de enfrentamento às desigualdades das relações de gênero. Além disso, o documento ratifica a garantia dos direitos afetivo-sexuais e sua expressão, recomendando que essas manifestações não sejam alvo de punição disciplinar. É conveniente mencionar, ainda, que este documento foi basilar para a estruturação das Diretrizes para atendimento às adolescentes privadas de liberdade no Sistema Nacional de Atendimento Socioeducativo (SINASE), o qual entrou em um processo de consulta pública em 2019, entretanto não foi ainda sancionado. Assim, permanece a carência desta importante resolução que instituiria parâmetros importantes para o atendimento das adolescentes.

Por meio dos dispositivos legais, percebe-se coerência no sentido de que a prática pedagógica no contexto socioeducativo deve atuar com vistas a promover novas formas de inserção social e de convivência. Assim, o processo de responsabilização para além do cumprimento judicial se atrela à promoção de um espaço dialógico e de reflexividade que permita uma compreensão a respeito do próprio comportamento em uma rede complexa e histórica, em que o respeito à alteridade possa se manifestar (VALENTE; LOPES DE OLIVEIRA, 2015). Existem, porém, diversas ações que precisam ser qualificadas desde o sentido técnico, perpassando pelos aspectos arquitetônicos, mas também nos aspectos culturais relativos ao exercício da atuação profissional na Socioeducação. A literatura aponta, nesse sentido, que o sistema socioeducativo, em especial as unidades de internação, ainda estão distantes de toda a lógica de garantia de direitos proposta pelos dispositivos legais (COSCIONI et al., 2017; NETO; CONSTANTINO; ASSIS, 2017). 


\section{RELACIONAMENTOS AMOROSOS, DIREITOS SEXUAIS E REPRODUTIVOS E MEDIDAS SOCIOEDUCATIVAS: POSSIBILIDADE DE INTERVENÇÕES PREVENTIVAS À VIOLÊNCIA EM RELACIONAMENTOS ÍNTIMOS}

Reitera-se o não reconhecimento dos direitos sexuais e reprodutivos à pessoa em condição de restrição de liberdade como um importante obstáculo às proposições a respeito dessa temática (RE e CIUFFOLETTI, 2020; REIS; ZUCCO, 2019; LOURENÇO et al., 2018). Esse panorama demanda que propostas interventivas com objetivo de prevenção à violência em relacionamento íntimo sejam amplamente discutidas, a fim de que os obstáculos institucionais possam ser considerados no desenho da proposta. A discussão a respeito da garantia desse direito pode se configurar como uma oportunidade de repensar o modo de funcionamento institucional, buscando o alinhamento com a doutrina da proteção integral.

As pesquisas que se dedicam a analisar relações amorosas no contexto socioeducativo priorizam o público masculino e informam que os desfechos positivos do relacionamento são mais proeminentes para eles (BACKMAN et al., 2017; KOERICH e RIBEIRO, 2017). Menor número de pesquisas tem se dedicado ao público feminino que está em processo de responsabilização por ato infracional (COSCIONI et al., 2017). É necessário, portanto, destacar que essa invisibilidade feminina traz prejuízos ao reconhecimento das peculiaridades dessa população quando inseridas em uma medida socioeducativa. Além disso, a partir do prisma da prevenção, os dados limitados representam um obstáculo ao reconhecimento da frequência e gravidade de determinado problema, bem como na compreensão de elos operacionais que se relacionam com sua manifestação (MURTA; SANTOS, 2015).

No que se refere à violação dos direitos sexuais e reprodutivos, a pesquisa de Diniz (2017) salienta uma alta prevalência, indicando que 14 das 18 adolescentes pesquisadas sofreram algum tipo de violência sexual antes da determinação de medida socioeducativa. A mesma pesquisa sinaliza que metade dessas adolescentes foram apreendidas com seus parceiros amorosos. Além disso, dentre as 18 adolescentes, uma estava grávida. Outro levantamento, realizado com 41 adolescentes, destacou que: 30 delas não estudavam, a maioria delas tinham mulheres como únicas responsáveis, 4 eram mães, 16 tinham familiares 


\section{Revista \\ Debates Insubmissos}

presos, 8 estavam em condição de rua antes da apreensão policial, e 19 relatavam que a família não tinha renda fixa e suficiente para garantir a própria subsistência (FROEMMING, 2016).

A partir dos indicadores apresentados, observa-se que os direitos elencados pelo ECA não se materializaram na vida dessas adolescentes e de suas famílias, contextualizando um processo de precarização de vida. Considera-se que a condição de vulnerabilidade observada nos levantamentos indica a necessidade de ações intersetoriais entre a Política Pública de Socioeducação e outras políticas públicas que viabilizem o acesso a direitos como escolarização, profissionalização, inserção em programas de transferência de renda, programas de cuidado à vítima de violência sexual, dentre outros. Nesse sentido, a proposta de prevenção à vitimização por violência em relacionamento íntimo seria mais um componente integrante de um projeto maior de intervenção socioeducativa, a qual estaria alinhavada pelo Projeto Político Pedagógico e permitiria dar sentido à vida institucional tanto da adolescente quanto dos profissionais. A realidade, entretanto, sinaliza que existem carências significativas tanto no diálogo das unidades com a rede de assistência comunitária, como também na oferta direta de atendimento qualificado (COSTA; SILVA, 2017).

As práticas culturais permissivas à violência podem invisibilizar a violência no relacionamento íntimo (MURTA et al., 2013). Em um estudo realizado em âmbito escolar, desenvolvido a partir de uma metodologia etnográfica, ficou assinalado a baixa busca por ajuda quando se trata das dimensões psicológica e moral da violência (CARVALHAES; CARDENAS, 2021). Nesse sentido, a proposição de intervenções a esse respeito pode se configurar como um espaço dialógico de negociação de sentidos a respeito do que seria a violência, sobre quando e como pedir ajuda. Além disso, em ambientes de restrição de liberdade relacionamentos homoafetivos têm sido descritos e, por vezes, também perpassados por violência (BARCINSKI, et al., 2013). A violência, de modo geral, foi descrita como uma resposta motivada pelos ciúmes e pelo medo da traição. Nesse sentido, pode-se cogitar como pertinente o desenvolvimento de habilidades de resolução não violenta dos conflitos. Além 
disso, o estereótipo de docilidade feminina pode interferir na percepção de sua autoria de agressões no âmbito institucional.

No que tange aos possíveis objetivos de uma intervenção de prevenção à violência em relacionamento íntimo, pode-se citar como exemplos: desenvolvimento de habilidades para manutenção de relacionamentos saudáveis; reconhecimento de tipos de violência perpetrada por parceiros íntimos e características de cada uma; conhecimento de alternativas não violentas para a resolução de conflitos nos relacionamentos afetivos ou sexuais; conhecimento acerca de recursos e instituições que podem prestar ajuda ao adolescente em situação de violência entre parceiros íntimos; e papel de amigos como interventores em situação de violência entre parceiros íntimos (LOURENÇO, et al., 2018). A escolha das estratégias utilizadas e dos destaques dados a determinada temática se alinharão com a escolha da lente teórica. A respeito de possíveis lentes teóricas para a construção da proposta, pode-se mencionar: a terapia cognitivo comportamental, as teorias feministas, o modelo transteórico da mudança comportamental, a teoria bioecológica do desenvolvimento humano, a teoria do apego, dentre outras (MURTA, et al., 2013; SCHINDELE; LINDROTH, 2021).

A definição de objetivos e lente teórica analítica auxiliará na compreensão a respeito do vetor da violência e seu impacto na saúde mental de adolescentes do sexo feminino que estão em processo de responsabilização. Por mais que a literatura aponte que a violência no namoro tenda a ser um fenômeno bidirecional (OLIVEIRA et al., 2014), os impactos dessa ocorrência na saúde física e psicológica feminina são mais notórios (GIORDANO, 2003), figurando como um importante eixo de atenção e cuidado em saúde, o qual necessita estar também como uma pauta do atendimento socioeducativo. Um estudo norte-americano realizado no âmbito da justiça juvenil indicou que, em uma amostra ( $n=305)$, aproximadamente $20 \%$ das adolescentes informaram ter sofrido violência física no namoro, $41 \%$ relataram ter sofrido violência física ou sexual no namoro e $18 \%$ narraram tentativa de suicídio pregressa com desejo de morrer (BUTTAR et al., 2013). Essas adolescentes, quando vinculadas em medidas que comportavam restrição da liberdade, apresentavam mais frequentemente queixas em saúde mental e tentativa de suicídio (BUTTAR et al., 2013; 


\section{Debates Insubmissos}

Revista

KELLY et al., 2007). É importante salientar que não foram identificados na literatura nacional estudos que se dediquem a investigar a prevalência de violência em relacionamentos amorosos para essa população. Por outro lado, as queixas em saúde mental também são proeminentes para a realidade nacional, sendo mais evidentes na medida socioeducativa de internação em estabelecimento educacional (DINIZ, 2017).

Esse vetor de violência não se manifesta somente na vida das adolescentes em processo de responsabilização, antes se repete frequentemente na história de vida de suas genitoras, as quais também relatam terem sofrido violência em relacionamento íntimo (ASSIS; CONSTANTINO, 2001). A presença de violência em âmbito familiar tem sido assinalada como fator de risco para a vitimização por violência em relacionamento íntimo, que representa um aspecto a ser refletido quando no desenvolvimento e oferta de intervenções (MCCLURE; PARMENTER, 2017). Nesse sentido, a cultura patriarcal estrutura uma pedagogia que perpassa várias instituições, inclusive, no âmbito familiar, assinalando prescrições ao comportamento dócil feminino mesmo quando se está em um relacionamento abusivo (BARCINSKI et al., 2013). Essas prescrições incidem nos processos de responsabilização de mulheres e adolescentes do sexo feminino, criando dispositivos que avaliam e garantam a docilização no cumprimento de uma medida socioeducativa (FROEMMING, 2016).

Ademais, o processo de inserção em medida socioeducativa restritiva de liberdade implica frequentemente no rompimento de relações amorosas a partir do abandono do namorado/parceiro amoroso (ASSIS; CONSTANTINO, 2001; BARCINSKI et al., 2013). Portanto, essa relação é interrompida por agente externo, sendo indicado, como componente de intervenção preventiva, a reflexão a respeito de como concretizar a transição entre relacionamentos perpassados pela violência para relacionamentos sem violência. Não obstante, o relacionamento homoafetivo, que pode ocorrer dentro da instituição, e a sexualidade feminina ainda são tabus. Essas dimensões da experiência afetivo-sexual ficam invisibilizadas ou mesmo sofrem com ações condenatórias (ASSIS; CONSTANTINO, 2001; FROEMMING, 2016; MORAES; BRÊTAS, 2016). Esse contexto se materializa em 
obstáculos na promoção de saúde focada no exercício autônomo da própria sexualidade e com respeito à diversidade sexual (BRASIL, 2015). Considera-se como propícia a inclusão da temática diversidade sexual e também sexualidade fluída no atendimento de adolescentes em cumprimento da medida socioeducativa de internação. Conforme abordado, a adolescência se configura como um momento de diversas experimentações, exercício da autonomia, construção de um sentido de vida e de identidade e todas essas atividades estão associadas em maior ou menor medida com a expressão da própria sexualidade.

As barreiras culturais baseadas na cultura patriarcal, na heteronormatividade e no adulcentrismo precisam ser pensadas na proposta de implementação de uma intervenção preventiva. A consideração dos aspectos culturais sexistas pode ser um dos elementos considerados, inclusive, no desenho da intervenção, refletindo-se como eles impactam o desenvolvimento e manutenção das relações amorosos e na existência ou não de violência nessas (MURTA et al., 2013; LOPES DE OLIVEIRA, COSTA; CAMARGO, 2018). Nesse ponto, seria indicado a realização de oficinas que promovessem o protagonismo juvenil discutindo normas e regras institucionais e acordos coletivos a respeito da convivência institucional, em especial, àquelas aplicáveis à expressão afetiva-sexual. Essas oficinas, porém, não podem limitar ou criar obstáculos ao acesso à visita íntima, direito já garantido na Lei Sinase. É sabido que no sistema penitenciário algumas instituições adotam burocracias próprias para permitir ou não o acesso à visita íntima, o que não deveria se repetir na Política Pública de Socioeducação (REIS; ZUCCO, 2019).

Além disso, a dimensão da própria sexualidade também é interpelada pelos estereótipos de gênero. As adolescentes em cumprimento de MSE, por exemplo, compreendem o sexo como um mecanismo para sustentar o relacionamento e como um meio para evitar a infidelidade masculina (MORAES; BRÊTAS, 2016). Esta representação associase frequentemente ao sofrimento psicológico das adolescentes pela ameaça de traição ou de término do relacionamento em virtude de estar vinculada a uma medida que comporte restrição da liberdade. Essa dimensão, entretanto, se configura de modo diferente quando se trata do público masculino, pois a "fiel” (mulher ou adolescente) se compromete a estar com o 
companheiro e auxiliá-lo no seu processo de cumprimento de pena ou MSE (BARCINSKI et al., 2013). Além disso, as adolescentes associam o exercício da própria sexualidade ao risco de contrair uma infecção sexualmente transmissível (MONTEIRO et al., 2011). Essas compreensões também são reproduzidas no atendimento socioeducativo ofertado, evidenciando a demanda por uma abordagem menos estereotipada a respeito de sexualidade e afetividade (MORAES; VITALLE, 2012; FROEMMING, 2016). As propostas de atendimento poderiam integrar temáticas como: modalidades de relacionamento, papéis de gênero, prazer, diversidade sexual, entre outros tópicos.

Soma-se a configuração relatada, o fato de que uma abordagem menos estereotipada seria sensível aos mecanismos culturais de controle da sexualidade feminina que condicionam representações tais como a "mulher banda". A "mulher banda" foi mencionada em uma pesquisa por um adolescente que cometeu ato infracional e seria aquela que tem vários parceiros e serviria para satisfação de desejos sexuais masculinos e não para relacionamentos estáveis, o que representa processos de objetificação feminina e limitação de sua conduta (COSTA; COSTA, 2015, p. 149). As representações desqualificadoras figuram como mecanismos de controle ao público feminino no exercício da busca por uma sexualidade prazerosa. Em decorrência da cultura sexista subjacente às prescrições decorrentes das relações de gênero, muitas vezes as adolescentes podem aderir a concepções desqualificadoras, as quais condicionam sofrimento e minoram a possibilidade de rompimento com modelos prepostos e que são limitantes ao seu desenvolvimento (COSTA, 2015).

Além dos desafios relacionados à prevenção da violência em relacionamento íntimo, é importante destacar que o relacionamento amoroso pode facilitar o processo de desistência do cometimento de atos infracionais, em especial, quando se está em uma relação de qualidade (BACKMAN et al., 2017; MCCARTHY; CASEY, 2008). Alguns indicadores importantes para percepção da qualidade da relação são: a experiência de suporte mútuo, compartilhamento da intimidade e padrão relacional não-violento (BACKMAN et al., 2017; GIORDANO, 2003; MCCARTHY; CASEY, 2008) A oportunidade de o relacionamento 
figurar como fator de proteção ao desenvolvimento associa-se a experiência de vínculo entre o casal, fortalecimento da autoestima mútua e estruturação de um projeto de vida comum (COSTA; ASSIS, 2006; KOERICH; RIBEIRO, 2017). Quanto à formação de vínculos, o relacionamento amoroso demonstrou ter um efeito mais imediato sobre os processos de desistência do cometimento de atos infracionais, enquanto a amizade implicaria em desfechos de desistência no longo prazo (BACKMAN et al., 2017). Compreender a possibilidade de risco e proteção inerente ao relacionamento amoroso é importante para que não se desenvolvam abordagens unicamente proibicionistas do relacionamento. Além disso, a partir do conhecimento a respeito de fatores de proteção que existam no contexto do relacionamento amoroso, pode-se discutir padrões relacionais, como reconhecê-los e formas de se proteger da vitimização por violência.

A integração do relacionamento amoroso e da constituição de uma família no projeto de vida é um fenômeno que se destaca no atendimento realizado ao público feminino e tratase de um direito sexual e reprodutivo (ASSIS; CONSTANTINO, 2001; BARCINSKI et al., 2013; MONTEIRO). As namoradas que visitam adolescentes do sexo masculino em unidade de internação sustentam uma representação de que o relacionamento pode ser uma forma de interromper a trajetória de envolvimento com atos infracionais do parceiro, em especial, quando se tem filhos (MESQUITA; PENSO, 2015). Essas relações, porém, tendem a reproduzir papéis femininos limitantes no relacionamento amoroso e na inserção social feminina em instituições (MESQUITA; PENSO, 2015). Em relação ao público feminino inserido no contexto de restrição de liberdade, o projeto de família construído com o "homem bom ou o homem mal", se configura como uma forma de reproduzir o estereótipo da necessidade de estar em um relacionamento amoroso para que se tenha sucesso em um projeto de vida longe de contextos de risco para o cometimento de infrações (BARCINSKI, 2009).

Apesar de se perceber que relacionamentos amorosos figuram como uma oportunidade para desenvolvimento da autoestima, o atendimento socioeducativo pode estruturar propostas de ampliação a respeito dos papéis designados às adolescentes. A promoção do acesso à escolarização, à saúde e à profissionalização pode ser base para a valorização de si e 


\section{Revista \\ Debates Insubmissos}

concepção de projetos de vidas com o exercício cidadão que ampliem a concepção a respeito do próprio destino após a medida socioeducativa (DINIZ, 2017). O processo de responsabilização pelo cometimento de ato infracional pode prover oportunidades de renegociação de sentido que permitam às adolescentes pensar em suas relações com instituições, pessoas e com a própria noção de futuro (COSTA; ASSIS, 2006).

Apresenta-se, como produto dessa reflexão, um diagrama de fatores que poderiam ser levados em consideração no desenho de uma intervenção que tenha por objetivo a prevenção à violência em relacionamento íntimo no contexto de Socioeducação. A figura foi construída como um percurso, porém a realidade institucional pode demandar ajustes e retroalimentação das fases.

Figura 1: Percurso de desenvolvimento de uma intervenção de prevenção à violência em relacionamento íntimo aplicável à socioeducação.

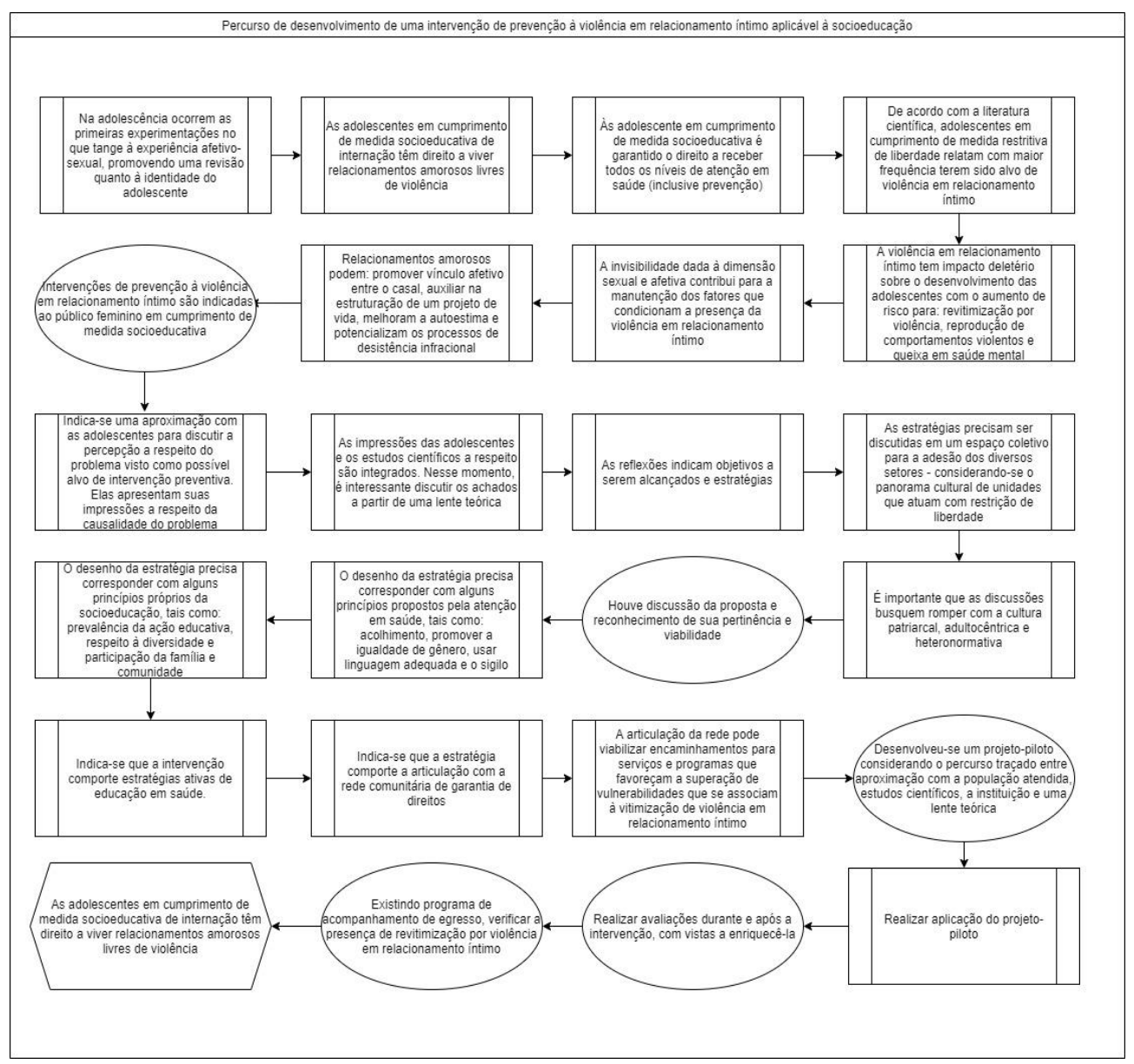

Fonte: os autores (2021) 


\section{CONSIDERAÇÕES FINAIS}

O presente ensaio teórico buscou analisar a prevenção da violência em relacionamento íntimo como meio de garantia de acesso a direitos sexuais e reprodutivos pelo público feminino inserido na Política Pública de Socioeducação. Durante o levantamento bibliográfico para a produção do artigo, observou-se um maior número de estudos dedicados à compreensão do risco do que da proteção potencializada pelos relacionamentos afetivosexuais nesta população. Essa tendência aponta uma representação de descrédito ao relacionamento amoroso na adolescência (GIORDANO, 2003), pensamento que pode embasar menor atenção aos fenômenos interpessoais e sociais que estão inerentes a ele. A representação de descrédito pode ser ainda mais proeminente quando se trata de adolescentes que cometeram um ato infracional, o que impacta diretamente o atendimento ofertado e na possibilidade de abordar essa temática de uma maneira que promova desenvolvimento das adolescentes que são atendidas na Socioeducação.

A discussão sobre os desfechos do relacionamento amoroso para a Socioeducação é importante em termos práticos, pois às equipes técnicas pode ser destinada a atribuição de autorizar ou não a entrada de namorado(a) para visitar uma adolescente em processo de responsabilização - quando se trata de medidas restritivas da liberdade. Além disso, este tema pode ser tratado em atendimentos individuais e coletivos, com vistas a discutir e promover modelos de relacionamento caracterizados por respeito, suporte mútuo e intimidade. Além disso, o desenvolvimento de habilidades para a negociação dos papéis e regras do relacionamento pode ser uma forma de trazer mais horizontalidade nas relações amorosas, o que pode figurar como um dos objetivos dos atendimentos realizados. A dinâmica da instituição de privação de liberdade, entretanto, necessita ser coerente com o discurso proposto, isto é, dar espaço para a qualificação das relações cotidianas e também maior horizontalidade destas.

A dimensão de ter vivência prévia de violência no relacionamento amoroso consiste em uma variável a ser levantada na história de vida da adolescente, haja vista seus desfechos em saúde mental. Além disso, ter sido vitimizada por violência em relacionamento íntimo 
representa um importante fator de risco para processos de revitimização futura (OLIVEIRA et al., 2014). O desenvolvimento de estratégias para enfrentamento da violência em relacionamentos íntimos e, mais abrangente que isso, da violência de gênero deve constar como uma pauta do atendimento prestado às adolescentes, matizando-a sempre com uma leitura crítica da realidade brasileira e fomentando a ideia de outros futuros possíveis.

A inclusão da discussão sobre relações de gênero para a Socioeducação ainda está em uma fase inicial, necessitando de maior engajamento nessa pauta e em outras que singularizam a experiência do adolescer. Existe uma diversidade de adolescências no âmbito socioeducativo, as quais são particularizadas pela experiência de viver sob os marcadores de gênero, classe e cor que, na vida das adolescentes, criam experiências de diversas inseguranças (BOCK, 2007; SHOEN-FERREIRA; SILVARES, 2010). A atenção a essas diversas adolescências é fundamental para que se estruturem ações pedagógicas comprometidas com o desenvolvimento humano, a saúde e a inserção cidadã da população que está em cumprimento de medida socioeducativa.

Apesar dos dispositivos legais, as indicações do enfrentamento aos problemas vividos pelas adolescentes são da ordem individual e familiar e não envolvem as políticas públicas, as quais são fundamentais para que se materialize a proteção à adolescência prevista em lei (BRASIL, 2006; FROEMMING, 2016). Os documentos técnicos produzidos no atendimento socioeducativo são perpassados pela crença de que a força de vontade seria suficiente para a transformação da própria trajetória de envolvimento com atos infracionais, sendo que os adolescentes reproduzem os discursos que ouvem a respeito de si, inclusive a representação negativa (FROEMMING, 2016; NETO; CONSTANTINO; ASSIS, 2017). A produção de documentos técnicos culpabilizadores do adolescente e de sua família mantém a lógica da situação irregular do Código de Menores, visão a ser superada pela doutrina de proteção integral inaugurada pelo ECA. Além disso, para se auxiliar um adolescente, é necessário ser menos condenatório e manter em vista que programas de responsabilização mais bemsucedidos estruturam-se a partir da superação dos fatores de risco da população atendida pelo oferecimento de suportes materiais, sociais e psicológicos (COSTA e ASSIS, 2006). 
Além disso, a ideia de futuro frágil pode condicionar a manutenção do comportamento de risco, portanto, o projeto de vida constitui uma dimensão a ser estruturada com a adolescente (COSTA; ASSIS, 2006). É importante que esse projeto de vida esteja pautado pela sua exequibilidade, associando-se aos aparelhos comunitários existentes e recursos e potencialidades observados, haja vista que o primeiro passo para que um projeto que possa promover desenvolvimento é ser pautado na confiança de potencial sucesso. Novamente, chama-se o atendimento socioeducativo para a ampliação do olhar e a integração com outras políticas públicas para que se preste mais suporte aos processos de mudança promovidos.

A discussão no âmbito científico no Brasil dos impactos do relacionamento amoroso em trajetórias de envolvimento com atos infracionais ainda é escassa. O presente artigo não pretende cobrir toda a complexidade que esta temática abarca. Porém, provoca a abordagem a novos temas no processo socioeducativo. Uma agenda de pesquisa poderia incluir estudos a respeito da prevalência de vitimização por violência de adolescentes em cumprimento de MSE; os fatores que, em um relacionamento, poderiam ocasionar risco para envolvimento com atos infracionais; a manifestação de violência em relacionamento de adolescentes em cumprimento de MSE; e a discussão de boas práticas em âmbito socioeducativo sobre a garantia de direitos afetivos e sexuais, dentre outros. Além disso, é necessário que os estudos explorem vias para promoção da saúde e desenvolvimento do público que está inserido no atendimento socioeducativo, a partir de seu protagonismo.

\section{REFERÊNCIAS}

ARÊAS NETO, Nilo Terra; CONSTANTINO, Patrícia; ASSIS, Simone Gonçalves de. Análise bibliográfica da produção em saúde sobre adolescentes cumprindo medidas socioeducativas de privação de liberdade. Physis: Revista de Saúde Coletiva, [S.L.], v. 27, n. 3, p. 511-540, jul. 2017. FapUNIFESP (SciELO). http://dx.doi.org/10.1590/s0103-73312017000300008.

ABREU, Samia; MURTA, Sheila Giardini. O Estado da Arte da Pesquisa em Prevenção em Saúde Mental no Brasil: uma revisão sistemática. Interação em Psicologia, [S.L.], v. 20, n. 1, p. 101-111, 15 dez. 2016. UFPR. http://dx.doi.org/10.5380/psi.v20i1.34790. 
ARRUDA, Jalusa Silva de. Breve panorama sobre a restrição e privação de liberdade de adolescentes e jovens no brasil. O Social em Questão, [S.L.], v. 1, n. 49, p. 355-381, 6 jan. 2021. Faculdades Católicas. http://dx.doi.org/10.17771/pucrio.osq.51140.

ASSIS, Simone Gonçalves de, CONSTANTINO, Patrícia. Filhas do mundo: infração juvenil feminina no Rio de Janeiro. Rio de Janeiro: Editora FIOCRUZ, 2001. 284p.

BACKMAN, Heidi; LAAJASALO, Taina; JOKELA, Markus; ARONEN, Eeva T.. Interpersonal Relationships as Protective and Risk Factors for Psychopathy: a follow-up study in adolescent offenders. Journal Of Youth And Adolescence, [S.L.], v. 47, n. 5, p. 1022-1036, 13 set. 2017. Springer Science and Business Media LLC. http://dx.doi.org/10.1007/s10964-017-0745-x.

BARCINSKI, Mariana. Centralidade de gênero no processo de construção da identidade de mulheres envolvidas na rede do tráfico de drogas. Ciência \& Saúde Coletiva, [S.L.], v. 14, n. 5, p. 1843-1853, dez. 2009. FapUNIFESP (SciELO). http://dx.doi.org/10.1590/s141381232009000500026 .

BARCINSKI, Mariana; CAPRA-RAMOS, Carine; WEBER, João L. A.; DARTORA, Tamires. O marianismo e a vitimização de mulheres encarceradas: formas alternativas de exercício do poder feminino. Ex Equo, S.L., v. 28, p. 87-100, 2013.

BARROS, João Paulo Pereira; BENICIO, Luis Fernando de Souza; SILVA, Dagualberto Barboza da; LEONARDO, Camila dos Santos; TORRES, Frida Jaina Popp. Homicídios Juvenis e os Desafios à Democracia Brasileira: implicações ético-políticas da psicologia. Psicologia: Ciência e Profissão, [S.L.], v. 37, n. 4, p. 1051-1065, dez. 2017. FapUNIFESP (SciELO). http://dx.doi.org/10.1590/1982-3703002892017.

BOCK, Ana Mercês Bahia. A adolescência como construção social: estudo sobre livros destinados a pais e educadores. Revista Semestral da Associação Brasileira de Psicologia Escolar e Educacional (Abrapee), [s. l], v. 11, n. 1, p. 63-76, jan. 2007. Semestral. Disponível em: https://www.scielo.br/j/pee/a/LJkJzRzQ5YgbmhonkKzVq3x/?format=pdf\&lang=pt. Acesso em: 12 abr. 2018.

BRASIL. Lei ${ }^{\circ}$ 12.594, de 18 de janeiro de 2012. Institui o Sistema Nacional de Atendimento Socioeducativo (Sinase), regulamenta a execução das medidas socioeducativas destinadas a adolescente que pratique ato infracional. Lei 12.594. Disponível em: http://www.planalto.gov.br/ccivil_03/_ato2011-2014/2012/lei/112594.htm. Acesso em: 18 abr. 2019. 
BRASIL. Lei no 8.069, de 13 de julho de 1990. Dispõe sobre o Estatuto da Criança e do Adolescente e dá outras providências. Diário Oficial [da] República Federativa do Brasil, Brasília, DF, 16 jul. $1990 . \quad$ Disponível em: <http://www.planalto.gov.br/ccivil_03/LEIS/L8069.htm\#art266>. Acesso em: 16 dez. 2018.

BRASIL. Mecanismo Nacional de Prevenção e Combate à Tortura (MNPCT). Adolescentes Privadas de Liberdade. Unidades socioeducativas femininas no Ceará, Distrito Federal, Paraíba e Pernambuco. Relatório de Missão Conjunta, 2019.

BRASIL. Ministério da Mulher, da Família e dos Direitos Humanos (MMFDH). Levantamento Anual SINASE 2017. Brasília: Ministério da Mulher, da Família e dos Direitos Humanos, 2019.

BRASIL. Ministério da Saúde. Secretaria de Atenção em Saúde. Departamento de Ações Programáticas Estratégicas. Cuidando de Adolescentes: orientações básicas para a saúde sexual e a saúde reprodutiva [recurso eletrônico] / Ministério da Saúde, Secretaria de Atenção em Saúde, Departamento de Ações Programáticas Estratégicas. Brasília: Ministério da Saúde, 2015. 44 p.

BRASIL. Por uma política nacional de execução das medidas socioeducativas: conceitos e princípios norteadores / Coordenação técnica Antonio Carlos Gomes da Costa. Brasília : Secretaria Especial dos Direitos Humanos, 2006. 64 p.

BRASIL. Presidência da República. Secretaria de Direitos Humanos (SDH). Plano Nacional de Atendimento Socioeducativo: Diretrizes e eixos operativos para o SINASE. Brasília: Secretaria de Direitos Humanos da Presidência da República, 2013. 39 p.

BRASIL. Presidência da República. Secretaria Especial dos Direitos Humanos. Conselho Nacional dos Direitos da Criança e do Adolescente. Sistema Nacional De Atendimento Socioeducativo -SINASE/ Secretaria Especial dos Direitos Humanos. Brasília-DF: CONANDA, 2006.

BUTTAR, Aliya; CLEMENTS-NOLLE, Kristen; HAAS, Joseph; REESE, Fritz. Dating Violence, Psychological Distress, and Attempted Suicide Among Female Adolescents in the Juvenile Justice System. Journal of Correctional Health Care, [S.L.], v. 19, n. 2, p. 101-112, 1 abr. 2013. Mary Ann Liebert Inc. http://dx.doi.org/10.1177/1078345812474639.

CARRETEIRO, Teresa. Adolescências e Experimentações Possíveis. In: MARRA, Marlene Magnabosco; COSTA, Liana Fortunato (ed.). Temas da clínica do adolescente e da família. São Paulo: Àgora, 2010. p. 15-24. 
CARVALHAES, Renata de Souza; CÁRDENAS, Claudia Mercedes Mora. "Namorar é só sofrência": violências na relação afetivo-sexual de adolescentes de uma escola na região costa verde, rio de janeiro, brasil. Ciência \& Saúde Coletiva, [S.L.], v. 26, n. 7, p. 2719-2728, jul. 2021. FapUNIFESP (SciELO). http://dx.doi.org/10.1590/1413-81232021267.09242021.

CERQUEIRA-SANTOS, Eldeer; MELO NETO, Othon Cardoso de; KOLLER, Silvia H. Adolescentes e Adolescências. In: HABIGZANG, Luisa Fernanda; DINIZ, Eva; KOLLER, Sílvia H. (ed.). Trabalhando com Adolescentes: Teoria e Intervenção Psicológica. Porto Alegre: Artes Médicas, 2014. p. 17-29.

COSCIONI, Vinicius; COSTA, Luiza Lins Araújo; ROSA, Edinete Maria; KOLLER, Sílvia Helena. O cumprimento da medida socioeducativa de internação no Brasil: uma revisão sistemática da literatura. Psico, [S.L.], v. 48, n. 3, p. 231, 29 set. 2017. EDIPUCRS. http://dx.doi.org/10.15448//1980-8623.2017.3.24920.

COSCIONI, Vinicius; FARIAS, Bruno Graebin de; GARCIA, Agnaldo; ROSA, Edinete Maria; KOLLER, Sílvia Helena. O convívio de adolescentes em medida socioeducativa de internação com a equipe técnica. Psico, [S.L.], v. 49, n. 2, p. 137-147, 24 ago. 2018. EDIPUCRS. http://dx.doi.org/10.15448/1980-8623.2018.2.27890.

COSCIONI, Vinicius; FARIAS, Bruno Graebin de; ROSA, Edinete Maria; KOLLER, Sílvia Helena. Significados do mundo do crime para adolescentes em medida socioeducativa de internação, Brasil. Revista Latinoamericana de Ciencias Sociales, Niñez y Juventud, [S.L.], v. 17, n. 2, p. 1-20, 15 jul. 2019. Fundacion Cinde. http://dx.doi.org/10.11600/1692715x.17214.

COSTA, Bruno Nogueira da Silva; COSTA, Liana Fortunato. Relação afetivo-sexual e violência em adolescentes que cometeram abuso sexual. In: MURTA, Sheila Giardini; BUCHERMALUSCHKE, Julia Sursis Nobre Ferro; DINIZ, Glaucia Ribeiro Starling (org.). Violência no Namoro: estudos, prevenção e psicoterapia. Curitiba: Editora Appris, 2015. Cap. 7. p. 141-156.

COSTA, Cláudia Regina Brandão Sampaio Fernandes da; ASSIS, Simone Gonçalves de. Fatores protetivos a adolescentes em conflito com a lei no contexto socioeducativo. Psicologia \& Sociedade, [S.L.], v. 18, n. 3, p. 74-81, dez. 2006. FapUNIFESP (SciELO). http://dx.doi.org/10.1590/s0102-71822006000300011.

COSTA, Daniela Lemos Pantoja Coelho de Oliveira. As adolescentes e a medida socioeducativa de internação: rompendo o silêncio. 2015. xviii, 158 f. Dissertação (Mestrado em Processos de Desenvolvimento Humano e Saúde). Universidade de Brasília, Brasília, 2015. 
COSTA, Nilson do Rosário; SILVA, Paulo Roberto Fagundes da. A atenção em saúde mental aos adolescentes em conflito com a lei no Brasil. Ciência \& Saúde Coletiva, [S.L.], v. 22, n. 5, p. 1467-1478, maio 2017. FapUNIFESP (SciELO). http://dx.doi.org/10.1590/141381232017225.33562016.

CUNHA, Gleicimar Gonçalves; LOPES DE OLIVEIRA, Maria Cláudia Santos; BRANCO, Ângela Uchoa. Universo afetivo-semiótico de adolescentes em medida socioeducativa de internação. Educação e Pesquisa, [S.L.], v. 46, p. 1-20, 2020. FapUNIFESP (SciELO). http://dx.doi.org/10.1590/s1678-4634202046220197.

DINIZ, Debora. Meninas fora da lei: a medida socioeducativa de internação no Distrito Federal / Debora Diniz. - Brasília: LetrasLivres, 2017. 110 p.

FROEMMING, Cecilia Nunes. Da seletividade penal ao percurso punitivo: a precariedade da vida das adolescentes em atendimento socioeducativo. 2016. 162 f. il. Tese (Doutorado em Política Social). Brasília: Universidade de Brasília, 2016.

GIORDANO, Peggy C.. Relationships in Adolescence. Annual Review Of Sociology, [S.L.], v. 29, n. 1, p. 257-281, ago. 2003. Annual Reviews. http://dx.doi.org/10.1146/annurev.soc.29.010202.100047.

HERRERA, Veronica M.; STUEWIG, Jeffrey. Gender Differences in Pathways to Delinquency: the impact of family relationships and adolescentdepression. Journal Of Developmental And Life-Course Criminology, [S.L.], v. 3, n. 2, p. 221-240, 24 nov. 2016. Springer Science and Business Media LLC. http://dx.doi.org/10.1007/s40865-016-0052-3.

JAVDANI, Shabnam; SADEH, Naomi; VERONA, Edelyn. Gendered social forces: a review of the impact of institutionalized factors on women and girls' criminal justice trajectories..

Psychology, Public Policy, And Law, [S.L.], v. 17, n. 2, p. 161-211, maio 2011. American Psychological Association (APA). http://dx.doi.org/10.1037/a0021957.

JIMENEZ, Luciene; ASSIS, Daniel Adolpho Daltin; NEVES, Ronaldo Gomes. Direitos sexuais e reprodutivos de crianças e adolescentes: desafios para as políticas de saúde. Saúde em Debate, [S.L.], v. 39, n. 107, p. 1092-1104, dez. 2015. FapUNIFESP (SciELO). http://dx.doi.org/10.1590/0103-110420151070385.

KELLY, Patricia J.; OWEN, Steven V.; PERALEZ-DIECKMANN, Esther; MARTINEZ, Elisabeth. Health Interventions With Girls in the Juvenile Justice System. Women'S Health Issues, [S.L.], v. 17, n. 4, p. 227-236, jul. 2007. Elsevier BV. http://dx.doi.org/10.1016/j.whi.2007.03.005. 
KOERICH, Bruna Rossi; RIBEIRO, Fernanda Bittencourt. Imaginários da infração juvenil: uma análise de três trajetórias da socioeducação de meio aberto. Iluminuras, [S.L.], v. 18, n. 44, p. 102-123, 16 ago. 2017. Universidade Federal do Rio Grande do Sul. http://dx.doi.org/10.22456/1984-1191.75736.

LOPES DE OLIVEIRA, Maria Cláudia Santos Lopes de; COSTA, Daniela Lemos Pantoja; CAMARGO, Carolina Knihs de. Infração juvenil feminina e socioeducação: um enfoque cultural e de gênero. Estudos e Pesquisas em Psicologia, [S.L.], v. 18, n. 1, p. 72-92, 20 dez. 2018. Universidade de Estado do Rio de Janeiro. http://dx.doi.org/10.12957/epp.2018.38110.

LORDELLO, Silvia Renata; MAUCH, Ana Gabriela Duarte (org.). Psicoterapia de Adolescentes e Jovens: práticas dialóicas e terapia narrativista como dispositivos clínicos. In: AMPARO, Deise Matos do; MORAIS, Renata Arouca; BRASIL, Kátia Tarouquella; LAZZARINI, Eliana Rigotto (org.). Adolescências: psicoterapias e mediações terapêuticas na clínica dos extremos. Brasília: Technopolitik, 2020. p. 425-438.

LORDELLO, Silvia Renata; SOUZA, Lara; COELHO, Letícia de Amorim Mota. Adolescentes e redes sociais: violência de gênero, sexting e cyberbullying no filme ferrugem. Nova Perspectiva Sistêmica, [S.L.], v. $28, \quad$ n. $\quad 65, \quad$ p. $68-81,31$ dez. $2019 . \quad$ Instituto Noos. http://dx.doi.org/10.38034/nps.v28i65.538.

LOURENÇO, Rafaela Gessner; FORNARI, Lucimara Fabiana; SANTOS, Danyelle Leonette Araújo dos; FONSECA, Rosa Maria Godoy Serpa da. Community interventions related to intimate partner violence among adolescents: scope review. Revista Brasileira de Enfermagem, [S.L.], v. 72, n. 1, p. 277-286, fev. 2019. FapUNIFESP (SciELO). http://dx.doi.org/10.1590/0034-7167-2018-0586.

MCCARTHY, Bill; CASEY, Teresa. Love, Sex, and Crime: adolescent romantic relationships and offending. American Sociological Review, [S.L.], v. 73, n. 6, p. 944-969, dez. 2008. SAGE Publications. http://dx.doi.org/10.1177/000312240807300604.

MCCLURE, Margaret M.; PARMENTER, Megan. Childhood Trauma, Trait Anxiety, and Anxious Attachment as Predictors of Intimate Partner Violence in College Students. Journal Of Interpersonal Violence, [S.L.], v. 35, n. 23-24, p. 6067-6082, 24 ago. 2017. SAGE Publications. http://dx.doi.org/10.1177/0886260517721894.

MESQUITA, Viviane de Souza Ferro de; PENSO, Maria Aparecida. A violência simbólica no relacionamento amoroso de adolescentes em cumprimento de medida socioeducativa. In: MURTA, Sheila Giardini; BUCHER-MALUSCHKE, Julia Sursis Nobre Ferro; DINIZ, Glaucia 
Ribeiro Starling (org.). Violência no Namoro: estudos, prevenção e psicoterapia. Curitiba: Editora Appris, 2015. Cap. 6. p. 123-140.

MINAYO, Maria Cecília de Souza. A Condição Juvenil no Século XXI. In: MINAYO, Maria Cecília de Souza; ASSIS, Simone Gonçalves de; NJAINE, Kathie (org.). Amor e violência: um paradoxo das relações de namoro e do : ficar : entre jovens brasileiros. Rio de Janeiro: Editora Fiocruz, 2011. Cap. 1. p. 17-44. Disponível em: https://static.scielo.org/scielobooks/4c6bv/pdf/ minayo-9788575413852.pdf. Acesso em: 18 abr. 2018.

MINAYO, Maria Cecília de Souza. Laços perigosos entre machismo e violência. Ciência \& Saúde Coletiva, [S.L.], v. 10, n. 1, p. 23-26, mar. 2005. FapUNIFESP (SciELO). http://dx.doi.org/10.1590/s1413-81232005000100005.

MONTEIRO, Estela Maria Leite Meirelles; NASCIMENTO, Carlos Alberto Domingues do; ALMEIDA FILHO, Antonio José de; ARAðJO, Ana Karina de Andrade; CARMO, Danilo Rafael Bezerra do; GOMES, Islan Moisalye Barbosa. Percepção de adolescentes infratoras submetidas à ação socioeducativa sobre assistência à saúde. Escola Anna Nery Revista de Enfermagem, Rio de Janeiro, v. 15, n. 2, p. 323-330, 2011.

MORAES, Silvia Piedade de; BRêTAS, José Roberto da Silva. Conceitos, comportamentos e educação em sexualidade:: a formação das condutas sexuais de adolescentes em conflito com a lei. Adolescência e Saúde, Rio de Janeiro, v. 13, n. 2, p. 18-25, set. 2016.

MORAES, Silvia Piedade de; VITALLE, Maria Sylvia de Souza. Direitos sexuais e reprodutivos na adolescência. Revista da Associação Médica, [s. l], v. 1, n. 58, p. 48-52, 2012.

MURTA, Sheil Giardini; SANTOS, Karine Brito dos. Desenvolvimento de programas preventivos e de promoção de saúde mental. In: MURTA, Sheila Giardini; LEANDROFRANÇA, Cristineide; SANTOS, Karine Brito dos; POLEJACK, Larissa (org.). Prevenção e Promoção em Saúde Mental: fundamentos, planejamento e estratégias de intervenção. Novo Hamburgo: Sinopsys, 2015. Cap. 7. p. 168-191.

MURTA, Sheila Giardini. Programas de prevenção a problemas emocionais e comportamentais em crianças e adolescentes: lições de três décadas de pesquisa. Psicologia: Reflexão e Crítica, [S.L.], v. 20, n. 1, p. 01-08, 2007. FapUNIFESP (SciELO). http://dx.doi.org/10.1590/s010279722007000100002 .

MURTA, Sheila Giardini; MOORE, Rafael Alberto; MIRANDA, Ana Aparecida Vilela; CANGUSSð, Eudes Diógenes Alves; SANTOS, Karine Brito dos; BEZERRA, Karinne Leissa Torres; VERAS, Lydia Galdino. Efeitos de um Programa de Prevenção à Violência no Namoro. 
Psico-Usf, [S.L.], v. 21, n. 2, p. 381-393, ago. 2016. FapUNIFESP (SciELO). http://dx.doi.org/10.1590/1413-82712016210214.

MURTA, Sheila Giardini; SANTOS, Bruna Roberta Pereira dos; MARTINS, Camila Perna Santos; OLIVEIRA, Brisa de. Prevenção primária à violência no namoro: uma revisão de literatura. Contextos Clínicos, [S.L.], v. 6, n. 2, p. 117-131, 1 out. 2013. UNISINOS Universidade do Vale do Rio Dos Sinos. http://dx.doi.org/10.4013/ctc.2013.62.05.

NETO, Nilo Terra Arêas; CONSTANTINO, Patrícia; ASSIS, Simone Gonçalves de. Análise bibliográfica da produção em saúde sobre adolescentes cumprindo medidas socioeducativas de privação de liberdade. Physis: Revista de Saúde Coletiva, [S.L.], v. 27, n. 3, p. 511-540, jul. 2017. FapUNIFESP (SciELO). http://dx.doi.org/10.1590/s0103-73312017000300008.

OLIVEIRA, Queiti Batista Moreira; ASSIS, Simone Gonçalves de; NJAINE, Kathie; PIRES, Thiago Oliveira. Namoro na adolescência no Brasil: circularidade da violência psicológica nos diferentes contextos relacionais. Ciência \& Saúde Coletiva, [S.L.], v. 19, n. 3, p. 707-718, mar. 2014. FapUNIFESP (SciELO). http://dx.doi.org/10.1590/1413-81232014193.19052013.

RE, Lucia; CIUFFOLETTI, Sofia. A pena recalcada: detenção e negação da sexualidade nos cárceres italianos. Revista de Estudos Constitucionais, Hermenêutica e Teoria do Direito, [S.L.], v. 12, n. 3, p. 350-381, 11 jan. 2021. UNISINOS - Universidade do Vale do Rio Dos Sinos. http://dx.doi.org/10.4013/rechtd.2020.123.03.

REIS, Camila Azevedo dos; ZUCCO, Luciana Patrícia. Saúde sexual e saúde reprodutiva no cárcere. Fronteiras: Revista Catarinense de História, [S.L.], n. 33, p. 66-86, 23 maio 2019. Universidade Federal da Fronteira Sul. http://dx.doi.org/10.36661/2238-9717.2019n33.10827.

RODRÍGUEZ, Susana Núñez; DAMÁSIO, Bruno Figueiredo. Desenvolvimento da identidade e sentido de vida na adolescência. In: HABIGZANG, Luisa Fernanda; DINIZ, Eva; KOLLER, Sílvia H. (ed.). Trabalhando com Adolescentes: Teoria e Intervenção Psicológica. Porto Alegre: Artes Médicas, 2014. p. 30-41

SCHINDELE, Anna Chuchu; LINDROTH, Malin. Sexual and reproductive health and rights (SRHR) among young people in secure state care and their non-incarcerated peers - a qualitative, descriptive and comparative study. European Journal Of Social Work, [S.L.], v. 24, n. 4, p. 657 670, 8 set. 2020. Informa UK Limited. http://dx.doi.org/10.1080/13691457.2020.1815658.

SCHOEN-FERREIRA, Teresa Helena; AZNAR-FARIAS, Maria; SILVARES, Edwiges Ferreira de Mattos. Adolescência através dos séculos. Psicologia: Teoria e Pesquisa, [S.L.], v. 26, n. 2, p. 227-234, jun. 2010. FapUNIFESP. http://dx.doi.org/10.1590/s0102-37722010000200004. 
SILVA, Nelson Pedro; GRANER-ARAðJO, Renata Cristina. O adolescente, tráfico de drogas e função paterna. Revista Psicologia Política, [s. l], v. 11, n. 21, p. 141-158, 2011.

VALENTE, Fernanda Pinheiro Rebouças; OLIVEIRA, Maria Cláudia Santos Lopes de. Para além da punição: (re)construindo o conceito de responsabilização socioeducativa. Estudos e Pesquisas em Psicologia, [S.L.], v. 15, n. 3, p. 853-870, 5 nov. 2015. Universidade de Estado do Rio de Janeiro. http://dx.doi.org/10.12957/epp.2015.19416.

Submetido: $30 / 06 / 2021$

Aprovado: 16/08/2021 